\title{
Exploring the Experiences of Pilots within Canadian General Aviation Flight Operations
}

\author{
Suzanne Kearns \\ The University of Western Ontario \\ Jennifer E. Sutton \\ Brescia University College
}

\begin{abstract}
Pilots track flight hours as a quantitative measure of expertise. This linear development of expertise may apply to technical skills; however, it has been suggested that the development of nontechnical expertise is associated with operational exposure to threats and errors (Thomas, 2004). Within this framework, nontechnical skills may develop at different rates depending upon exposure to different threats and errors within specific types of flight operations. The present investigation examined the threats, errors, and nontechnical skills of pilots within Canadian general aviation operations. One hundred thirty narratives describing real-world scenarios were gathered from pilots with an online self-report Hangar Talk Survey (HTS). Several threats, errors, and nontechnical skills were significantly associated with specific types of operations. This suggests that the rate of nontechnical skill development may additionally be linked to the type of operation a pilot is involved in, rather than to the number of flight hours alone.
\end{abstract}

\section{Introduction}

Canada offers pilots great diversity in geographic terrain, climate, and aviation operations, coupled with unparalleled access to uncontrolled airspace. In 2008, there were 37,944 recreational and 24,598 professional licensed pilots in Canada (Transport Canada, 2010). An important component of Canada's aviation industry is general aviation (GA), which includes all operations outside of scheduled airline or military operations, including commercial operations such as charters, helicopter operations, bush flying, recreational flying, and flight instruction. GA is the largest aviation sector in Canada, with more aircraft and pilots than in the airlines and military combined (Kearns, 2009).

Within the broader aviation industry, it is accepted that all pilots require a combination of technical and nontechnical skills. Technical skills are those required to safely complete standard operating procedures, including psychomotor (hands-and-feet) and cognitive (operational knowledge) skills. Nontechnical skills are less specific, referring to broad cognitive and interpersonal skills. Nontechnical skills are often considered supplementary safety skills that are beyond the scope of what is included in traditional pilot training such as situation awareness, communication, workload management, and decision making. Safety skills are a significant concern in GA, as $98 \%$ of aviation accidents in Canada in 2010 occurred within GA (Tranportation Safety Board, 2011). Unfortunately, GA pilots have little access to nontechincal training to improve 
safety. Instead, the industry relies on pilots developing crucial nontechincal skills through the naturalistic process of building real-world flying experience.

This method of building expertise through experience is addressed by the threat and error management (TEM) perspective on nontechnical skill development. TEM suggests that nontechnical skills develop as a result of a pilot being exposed to threats and committing errors (Helmreich, Merritt, \& Wilhelm, 1999; Thomas, 2004). A threat is defined as a condition that has the potential to negatively impact flight safety, such as bad weather or an incorrect instruction from Air Traffic Control (ATC), while an error is defined as a response, or lack of a response, commited by the flight crew that diverges a flight from its intended course (Thomas, 2004). Errors can include a pilot intentionally breaking a regulation or may result from lack of proficiency in a particular skill or maneuver.

Nontechnical skill development is especially important in GA, since a large proportion of pilots within this sector are in an "hours-building" phase of their career. Typically, new commercial pilots in Canada work in this sector for a period of time as a means to build sufficient hours of flight experience to apply for a flying career in the airline industry. From a hiring perspective, the emphasis is on the pilots' number of hours, with little consideration given to the type of operation in which the hours were conducted (G. Priestley, personal communication, October 20, 2011). That is, the industry typically assumes that all hours-of-experience on a similar aircraft are equal, regardless of how those hours were spent. However, a similar type of aircraft may be used for flight instructing, a small charter, mountain flying, or a recreational trip. These different operations likely result in pilots encountering different threats and errors, meaning that pilots with the same number of hours in a particular aircraft may have meaningful variations in experience. Based on the TEM concept of skill development, therefore, the varying experience with threats and errors may lead to different levels of nontechnical expertise.

Expertise is important for pilots across all sectors of aviation, as experts demonstrate unique characteristics that result in improved performance over novices, including improved decision making, the ability to accurately predict future flight states, and compensation for cognitive and psychomotor declines that naturally occur with age on flight-related tasks (Doane, Sohn, \& Jodlowski, 2004; Morrow et al., 2009; Taylor, Kennedy, Noda, \& Yesavage, 2007). Expertise is characterized by an individual's progression from understanding problems in a literal and superficial sense, to the ability to understand in a principled, articulated, and conceptual manner (Chi, 2006). Contrary to popular opinion, expertise is not developed through the passing of time or individual maturation. The key to developing expertise is accumulating skill through deliberate practice and/or experience, such as operational exposure to threats and errors (Ericsson, 2004). Based on the "craft guilds" terminology of the Middle Ages, Hoffman (1996) presented the following framework to describe the stages of expertise: naiveté, novice, initiate, apprentice, journeyman, expert, and master. Pilot technical expertise, based on a pilot's number of hours, can be mapped over Hoffman's stages in a linear fashion, as 
presented in Table 1. However, if threats or errors vary depending upon categories of flight operation, it is expected that nontechnical expertise may develop with operational specificity. For example, a master who operates primarily within ab initio flight instruction would not be expected to demonstrate expert attributes within a charter environment, even if operating the same type of aircraft and possessing the same number of hours.

Table 1. The Stages of Expertise Within a Professional Pilot Career

\begin{tabular}{|c|c|c|}
\hline Stage & $\begin{array}{l}\text { Application to professional } \\
\text { pilot career }\end{array}$ & $\begin{array}{l}\text { Approximation of experience } \\
\text { in each stage }\end{array}$ \\
\hline Naiveté & A person who is ignorant of flying & No flight training experience \\
\hline Novice & $\begin{array}{l}\text { A person with minimal exposure to } \\
\text { piloting }\end{array}$ & $\begin{array}{l}\text { Begun flight training but has not } \\
\text { yet completed a solo flight }\end{array}$ \\
\hline Initiate & $\begin{array}{l}\text { A person with introductory flight } \\
\text { instruction }\end{array}$ & $\begin{array}{l}\text { Has completed a solo flight but } \\
\text { does not hold a license or rating }\end{array}$ \\
\hline Apprentice & $\begin{array}{l}\text { A person undergoing a course of } \\
\text { instruction (either from a flight } \\
\text { instructor or by working with and } \\
\text { observing senior pilots) }\end{array}$ & $\begin{array}{l}\text { After completing a private pilot } \\
\text { license but with less than } 1000 \\
\text { hours total time (Durso and Dattel, } \\
2006 \text { ) }\end{array}$ \\
\hline Journeyman & $\begin{array}{l}\text { Someone who can competently } \\
\text { perform the professional duties of a } \\
\text { pilot unsupervised }\end{array}$ & $\begin{array}{l}\text { After completing } 1000 \text { hours total } \\
\text { time but before completing } 5 \text { years } \\
\text { or } 4000 \text { hours flight experience - } \\
\text { however, some professionals may } \\
\text { remain at this level throughout theil } \\
\text { careers }\end{array}$ \\
\hline Expert & $\begin{array}{l}\text { A pilot who reliably demonstrates } \\
\text { accuracy in piloting, who can } \\
\text { respond to situations automatically } \\
\text { with little cognitive effort, and who } \\
\text { can competently deal with } \\
\text { unexpected challenging situations }\end{array}$ & $\begin{array}{l}\text { More than } 4000 \text { hours flight } \\
\text { experience, who demonstrates } \\
\text { expert attributes (accuracy, } \\
\text { automatic reactions, competency in } \\
\text { challenging situations) }\end{array}$ \\
\hline Master & $\begin{array}{l}\text { Any expert or journeyman who } \\
\text { possesses the qualifications to } \\
\text { teach those at a lower level of } \\
\text { expertise; the judgments of masters } \\
\text { establish standard procedures } \\
\text { within their domain }\end{array}$ & $\begin{array}{l}\text { A journeyman or expert who is a } \\
\text { qualified chief flight instructor }\end{array}$ \\
\hline
\end{tabular}

While some data exist on the threats and errors encountered by airline pilots (Thomas, 2004), little empirical evidence exists describing the threats and errors pilots encounter within GA. The variety of GA operations in Canada means that while pilots keep track of 
their number of flight hours as a measure of their expertise, flight hours alone may not precisely gauge pilot skill. Therefore, the purpose of the current investigation was to begin to characterize the experiences of pilots in Canadian GA by examining the threats and errors that occur in different operations, and the nontechnical skills that are used in those operations. Pilots self-reported significant flying events that occurred during the hours-building phase of their career. The scenarios were analyzed for descriptions of threats, errors, and the use of nontechnical skills in the type of operation described. If particular operations, including single versus multi-crew situations, are differentially associated with certain threats, errors, and nontechnical skills, hiring practices may need to be modified to look not only at the number of hours a pilot possesses but to also consider the type of operation within which those hours were conducted. Therefore, the current study sought to determine whether, within events that pilots deemed significant, the threats, errors, and nontechnical skills reported differed according to the type of operation.

\section{Method}

\section{Participants}

The present investigation used an Internet-based self-report survey (the Hangar Talk Survey, HTS) to solicit data on threats, errors, and nontechnical skills. The survey was published online for a period of 10 months. Participants were recruited through pilot groups, professional aviation organizations, flying schools, and a pilot magazine, as well as participant-to-participant through social media utilities.

A total of 849 people visited the survey website. Of those, 704 agreed to the consent form and gained access to the survey. The total number of people who completed the survey was 143 , for an overall completion rate of $20 \%$. Thirteen responses were excluded from the current analysis due to incomplete or incorrect responses and responses that did not describe Canadian operations, resulting in a total of 130 valid responses. The respondents' hours of flying experience were categorized in several ways. The mean number of hours when encountering the scenario described in the survey was $1028(S D=$ $1090)$, while the mean hours in the aircraft described in the scenario was $320(S D=375)$ and the mean hours in the type of operation at the time of the scenario was 488 (SD = 5484).

The study was approved by the Research Ethics Board of Seneca College, Markham, Ontario, where the web survey was hosted.

\section{Procedure}

Materials. The HTS was a self-report survey created to gather narrative descriptions of scenarios pilots had encountered, including the type of operation they were involved in at the time, the impact of the event on their career, and whether they would react differently if encountering the same scenario in the future. Data on the impact of the 
event reported in the scenario on the pilot, and the effect of the scenario on future decision making, were addressed in Kearns and Sutton (2011); therefore, the current analysis is focused on the associations of operation type and crew type with threats, errors, and nontechnical skill utilization in the reported scenarios. The survey was written in English and included an open-ended narrative question and closed-ended multiplechoice questions. It took approximately 20 to 25 minutes to complete the survey. Anonymity was guaranteed.

The relevant survey items for the current investigation were as follows:

- Based on your real-world flying experiences, after achieving a commercial pilot's license but before being employed with a major airline, please think of a situation you have encountered that was outside the limits of standard performance and required you to think creatively to maintain safe flight. The scenario should describe a situation where you were challenged as a pilot and ultimately learned a valuable lesson.

- Approximately how many hours did you have when you encountered this scenario?

- Approximately how many hours did you have in the aircraft type when you encountered the scenario?

- Approximately how many hours did you have in the type of operation (medevac, instructing, charter, etc.) when you encountered the scenario?

- Approximately how many hours do you have now?

- Were you in a single-crew or multi-crew operation when you encountered the scenario?

Identification of Threats, Errors, and Nontechnical Skills. The narrative description of each scenario was subjected to a data cleaning process. Valid survey responses were distributed to three professional pilots who acted as reviewers. Reviewers were given instructions on how to identify threats, errors, and nontechnical skills within the narrative responses. Reviewers also identified the type of operation described within the scenario. Each survey response was reviewed by all three pilots. If a consensus was not reached, the reviewers worked with the first author to determine the most appropriate response in a data cleaning roundtable.

As an example, the following is an excerpt from one of the Hangar Talk Survey narratives (identifying details have been removed):

It was my leg to fly and we were operating in IFR although not down to approach minimums. We were behind schedule from the start of the flight. During descent, I briefed the approach.

When I finished, I asked the captain, who had a bit of a reputation, if he had any questions. He looked right at me and said “That's (expletive) stupid. The weather isn't that bad. Just go a couple hundred feet lower out here and you'll get below the cloud and it will save us 5 minutes.” I explained that I couldn't legally get to that altitude 
without busting a few limits. He pressed his point by saying that it was flat and there were no mountains or towers for me to hit.

I flat out refused to bust any limits and told the captain that this was the only legal way we could get down below the cloud and that if he didn't like it that he could take control from me and that I would be forced to follow it up with management. He didn't take control and he never again asked me to bust another limit. I was new with the company and was intimidated by this captain. What I should have done was to follow it up with Management and document the situation.

This narrative was tagged with the threats of "operational pressure" and "weather," as the pilot had to deal with an over-authoritative captain along with poor weather conditions. In addition, it was determined that the pilot utilized the nontechnical skills of "decision making" and "communication," as he or she was challenged to choose the right course of action, despite the insistence of the captain to continue, and had to communicate that decision effectively.

\section{Results}

\section{Descriptive Analysis}

Operations. The types of operation identified by reviewers are presented in Table 2 . Of the 130 survey responses, $77 \%$ described scenarios flown by a single pilot, while $23 \%$ described multi-crew operations.

Table 2. Operations Reported in the Scenarios

\begin{tabular}{lrr}
\hline \multicolumn{1}{c}{ Type of operation } & Frequency & Percentage \\
\hline Recreational flight & 42 & $32 \%$ \\
Charter & 23 & $18 \%$ \\
Flight instruction & 20 & $15 \%$ \\
Bush flying & 11 & $9 \%$ \\
Commuter & 4 & $3 \%$ \\
Medical evacuation & 3 & $2 \%$ \\
Ferry flight & 3 & $2 \%$ \\
Cargo & 2 & $2 \%$ \\
Helicopter & 2 & $2 \%$ \\
Survey flight & 1 & $1 \%$ \\
Sightseeing & 1 & $1 \%$ \\
Fire patrol & 1 & $1 \%$ \\
Search and rescue & 1 & $1 \%$ \\
Regional airline & 1 & $1 \%$ \\
Not identifiable & 15 & $12 \%$ \\
Total & 130 & \\
\hline
\end{tabular}


Threats. Threats and errors were identified based on the narrative description of the scenario and were separated for analysis purposes. The frequencies and percentages of threats identified within the HTS are presented in Table 3.

Errors. Table 4 describes the frequency and percentage of identified errors identified within HTS responses.

Table 3. Threats Identified in Survey Responses

\begin{tabular}{lrr}
\hline \multicolumn{1}{c}{ Threat } & Frequency $^{\mathrm{a}}$ & Percentage \\
\hline Weather & 45 & $34 \%$ \\
Aircraft malfunction & 39 & $29 \%$ \\
Operational pressure & 11 & $8 \%$ \\
Traffic & 6 & $5 \%$ \\
ATC Command & 7 & $5 \%$ \\
Terrain & 6 & $5 \%$ \\
Student pilot error during & 7 & $5 \%$ \\
$\quad$ instruction & & \\
Passenger event & 5 & $4 \%$ \\
Ground handling event & 3 & $2 \%$ \\
Airport condition & 2 & $1 \%$ \\
Communication threat & 1 & $1 \%$ \\
Inappropriate SOP & 1 & $1 \%$ \\
Pilot incapacitation & 1 & $1 \%$ \\
Total & 134 & \\
\hline
\end{tabular}

${ }^{\mathrm{a}}$ Threat data from narratives describing Canada-specific operations in Kearns and Sutton (2011).

Table 4. Errors Identified in Survey Responses

\begin{tabular}{lrr}
\hline \multicolumn{1}{c}{ Error } & Frequency $^{\text {a }}$ & Percentage $^{-}$ \\
\hline Decision making error & 41 & $47 \%$ \\
Procedural & 17 & $19 \%$ \\
Proficiency & 16 & $18 \%$ \\
Intentional noncompliance & 7 & $8 \%$ \\
Communication error & 7 & $8 \%$ \\
Total & 88 & \\
\hline \multicolumn{2}{c}{ E Error data from narratives describing Canada-specific } \\
operations in Kearns and Sutton (2011). \\
\hline
\end{tabular}

Nontechnical Skills. The nontechnical skills (NTS) identified within HTS responses are presented in Table 5. 
Table 5. Nontechnical Skills Identified in Survey Responses

\begin{tabular}{lrr}
\hline \multicolumn{1}{c}{ Nontechnical skill } & Frequency $^{\mathrm{a}}$ & Percentage \\
\hline Decision making & 113 & $39 \%$ \\
Communication & 76 & $26 \%$ \\
Situation awareness & 58 & $20 \%$ \\
Task management & 43 & $15 \%$ \\
Total & 290 & \\
${ }^{2}$ Error data from narratives describing Canada-specific \\
operations in Kearns and Sutton (2011). \\
\hline
\end{tabular}

\section{Associations Between Type of Operation and Threats, Errors, and Nontechnical Skills}

Since some operation types were reported infrequently, broader categories were created for analysis purposes. The Charter Flight category was expanded to include sightseeing, cargo, ferry flights, and regional airline operations. An "Other" category was created to include operational types with few instances, including bush flying, helicopter, medical evacuation, fire patrol, and search and rescue operations. Therefore, four main categories of operations were used in the analysis: Charter Flights, Recreational Flights, Flight Instruction, and Other. Associations between type of operation and threats, errors, and nontechnical skills were evaluated using chi-square tests or, for tests where at least one cell had an expected count less than 5, Fisher's exact test.

Threats. Chi-square analyses revealed that Operation Type was significantly associated with the presence of Operational Pressure, $\chi^{2}(3)=10.48, p=.01$, but associations with Weather, $\chi^{2}(3)=7.31, p=.06$, and Aircraft Malfunction, $\chi^{2}(3)=4.90, p$ $=.18$, were not significant. Fisher's exact tests showed a significant association between Operation Type and Airport Condition, $p=.02$, and Student Pilot Error, $p<.001$. Associations between Operation Type and Traffic, Air Traffic Control, Terrain, Passenger Events, Communication, violations of Standard Operating Procedure, Pilot Incapacitation, and Ground Events were not significant, all $p$ values were greater than .05. Contingency tables for the significant associations of Operation Type with Operational Pressure, Airport condition, and Student Pilot Error are shown in Tables 6, 7, and 8 , respectively. 
Table 6. Contingency Table for the Association of Operation Type and Operational Pressure

\begin{tabular}{lccc}
\hline & \multicolumn{3}{c}{ Operational Pressure } \\
\cline { 2 - 4 } \multicolumn{1}{c}{ Operation Type } & No & Yes & Total \\
\hline Recreational Flight & 42 & 0 & 42 \\
Charter Flight & 27 & 7 & 34 \\
Flight Instruction & 19 & 1 & 20 \\
Other & 17 & 2 & 19 \\
Total & 105 & 10 & 115 \\
\hline
\end{tabular}

Table 7. Contingency Table for the Association of Operation Type and Airport Condition

\begin{tabular}{lccc}
\hline & \multicolumn{3}{c}{ Airport Condition } \\
\cline { 2 - 4 } \multicolumn{1}{c}{ Operation Type } & No & Yes & Total \\
\hline Recreational Flight & 42 & 0 & 42 \\
Charter Flight & 33 & 1 & 34 \\
Flight Instruction & 20 & 0 & 20 \\
Other & 16 & 3 & 19 \\
Total & 111 & 4 & 115 \\
\hline
\end{tabular}

Table 8. Contingency Table for the Association of Operation Type and Student Pilot Error

\begin{tabular}{lccc}
\hline & \multicolumn{3}{c}{ Airport Condition } \\
\cline { 2 - 4 } Operation Type & No & Yes & Total \\
\hline Recreational Flight & 41 & 1 & 42 \\
Charter Flight & 34 & 0 & 34 \\
Flight Instruction & 14 & 6 & 20 \\
Other & 19 & 0 & 19 \\
Total & 108 & 7 & 115 \\
\hline
\end{tabular}

Errors. Chi-Square tests showed that Operation Type was significantly associated with Intentional Noncompliance, $\chi^{2}(3)=8.60, p=.04$, but not Decision Error, $\chi^{2}(3)=$ $6.16, p=.10$. Fisher's exact tests showed a significant association of Operation Type with Proficiency Errors, $p=.02$, but not with Procedural or Communication Errors, both $p$ values were greater than .05 . Contingency tables for the significant associations of Operation Type with Intentional Noncompliance and Proficiency Errors are presented in Tables 9 and 10, respectively. 
Table 9. Contingency Table for the Association of Operation Type and Intentional Noncompliance Errors

\begin{tabular}{lccc}
\hline & \multicolumn{3}{c}{ Intentional Noncompliance } \\
\cline { 2 - 4 } Operation Type & No & Yes & Total \\
\hline Recreational Flight & 42 & 0 & 42 \\
Charter Flight & 31 & 3 & 34 \\
Flight Instruction & 20 & 0 & 20 \\
Other & 16 & 3 & 19 \\
Total & 109 & 6 & 115 \\
\hline
\end{tabular}

Table 10. Contingency Table for the Association of Operation Type and Proficiency Errors

\begin{tabular}{lccc}
\hline & \multicolumn{3}{c}{ Proficiency Errors } \\
\cline { 2 - 4 } Operation Type & No & Yes & Total \\
\hline Recreational Flight & 35 & 7 & 42 \\
Charter Flight & 32 & 2 & 34 \\
Flight Instruction & 14 & 6 & 20 \\
Other & 19 & 0 & 19 \\
Total & 100 & 5 & 115 \\
\hline
\end{tabular}

Nontechnical Skills. Chi-square tests showed a significant association of Operation Type and Communication skills, $\chi^{2}(3)=15.65, p=.001$, but not Situation Awareness, $\chi^{2}(3)=0.36, p=.94$, Task Management, $\chi^{2}(3)=0.48, p=.92$, or Decision Making, $\chi^{2}(3)$ $=2.97, p=.40$. A contingency table for the association of Operation Type and Communication Skills is presented in Table 11.

Table 11. Contingency Table for the Association of Operation Type and Communication Skills

\begin{tabular}{lccc}
\hline & \multicolumn{3}{c}{ Communication Skills Utilized } \\
\cline { 2 - 4 } Operation Type & No & Yes & Total \\
\hline Recreational Flight & 30 & 12 & 42 \\
Charter Flight & 10 & 24 & 34 \\
Flight Instruction & 9 & 11 & 20 \\
Other & 13 & 6 & 19 \\
Total & 62 & 53 & 115 \\
\hline
\end{tabular}




\section{Associations Between Flight Crew Type and Threats, Errors, and Nontechnical Skills}

As with Operation Type, associations between type of flight crew (single or multicrew) and threats, errors, and nontechnical skills were evaluated using chi-square tests or, for tests where at least one cell had an expected count less than 5, Fisher's exact test.

Threats. Fisher's exact test showed a significant association between Crew Type and Operational Pressure, $p=.02$, but no association between Crew Type and Traffic, Air Traffic Control, Airport conditions, Terrain, Passenger Events, Communication Events, Student Pilot Errors, Inappropriate SOP, Pilot Incapacitation, or Ground Events, all $p$ values were greater than .05. Also, chi-square tests showed no significant associations between Crew Type and Weather, $\chi^{2}(1)=.0004, p=.98$, or Crew Type and Malfunction, $\chi^{2}(1)=0.54, p=.46$. The contingency table for the significant association of Crew Type and Operational Pressure is shown in Table 12.

Table 12. Contingency Table for the Association of Crew Type and Operational Pressure

\begin{tabular}{lccc}
\hline & \multicolumn{3}{c}{ Operational Pressure } \\
\cline { 2 - 4 } Crew Type & No & Yes & Total \\
\hline Single pilot & 81 & 4 & 85 \\
Multi-Crew & 24 & 6 & 30 \\
Total & 105 & 10 & 115 \\
\hline
\end{tabular}

Errors. Fisher's exact tests showed Crew Type was not significantly associated with Intentional Noncompliance, Procedural Errors, Communication Error, or Proficiency Errors, all $p$ values were greater than .05, and a chi-square test showed no significant association between Crew Type and Decision Error, $\chi^{2}(1)=0.57, p=.45$.

Nontechnical Skills. Chi-square tests revealed a significant association between Crew Type and the use of Communication skills, $\chi^{2}(1)=23.42, p<.001$, and an association with Situation Awareness that approached significance, $\chi^{2}(1)=3.79, p=.051$. Crew Type was not significantly associated with Task Management skills, $\chi^{2}(1)=1.73, p=.19$, or Decision Making skills, $\chi^{2}(1)=1.58, p=.21$. The contingency table for Crew Type and Communication Skills is shown in Table 13, and the contingency table for Crew Type and Situation Awareness is presented in Table 14. 
Table 13. Contingency Table for the Association of Crew Type and Usage of Communication Skills

\begin{tabular}{lccc}
\hline & \multicolumn{3}{c}{ Communication Skills Utilized } \\
\cline { 2 - 4 } Crew Type & No & Yes & Total \\
\hline Single pilot & 55 & 30 & 85 \\
Multi-Crew & 4 & 26 & 30 \\
Total & 59 & 56 & 115 \\
\hline
\end{tabular}

Table 14. Contingency Table for the Association of Crew Type and Situation Awareness

Situation Awareness

\begin{tabular}{lccc}
\cline { 2 - 4 } Crew Type & No & Yes & Total \\
\hline Single pilot & 42 & 43 & 85 \\
Multi-crew & 21 & 9 & 30 \\
Total & 63 & 52 & 115 \\
\hline
\end{tabular}

\section{Discussion}

The current investigation used an online Hangar Talk Survey (HTS) to gather narrative descriptions of flying events encountered by pilots within Canadian GA operations. Within the narratives, three pilot reviewers identified threats, errors, and nontechnical skills. Analyses revealed that the threats of operational pressure, airport condition, and student pilot error were significantly associated with the type of operation. In addition, a significant association with operation type was identified for the errors of intentional noncompliance and proficiency, as well as the nontechnical skill of communication. The analysis also revealed that the type of crew, whether single-pilot or multi-crew, was associated with the threat of operational pressure and the nontechnical skill of communication.

A number of threats were differentially associated with operation type in the scenarios reported by pilots. The threat of airport condition refers to environmental challenges during takeoff, landing, or taxi, and was most often reported within the Other category, which included bush flying, helicopter, medical evacuation, fire patrol, and search and rescue operations. Within Canada, these activities may be conducted in rural areas, on floats that allow takeoffs and landings on water, or into confined areas that are not registered aerodromes. Although pilots within these operations receive specialized training to deal with such conditions, pilots within other types of operations would be unlikely to face these challenges. Moreover, if nontechnical skills are related to the experience of particular threats, pilots with experience in these sectors should be better able to deal with airport challenges than pilots in other sectors. 
It is perhaps unsurprising that another threat, student pilot error, was more commonly encountered during flight instruction than other operations. A student pilot error during flight instruction refers to a mistake made by a student pilot that threatens the safety of the flight while the responding pilot is acting as a flight instructor. Flight instructors are trained in how to teach students, but little attention is paid to how to manage the threat of a student pilot error. This represents a significant risk for new pilots who choose flight instruction as a means to build skills and experience, as most instructors are still apprentices themselves yet must deal with student pilot errors—often combined with the stress of a panicked student.

The threat of operational pressure was significantly associated with operational type, most identified within charter flight operations. As charter operations are more likely than other GA operations to be operated by a multi-crew, it follows that the crew type in the reported scenarios was also associated with the threat of operational pressure. Multipilot flight crews appeared more likely to be affected by operational pressure than singlepilot crews. It is unclear why multi-pilot crews would be more susceptible to this threat, but it could be due to the presence of an over-authoritative senior crewmate, which would only impact multi-pilot crews. Future investigations may explore whether human factors instruction, focusing on communication, personal limitations, team-working, leadership, and decision making skills, can mitigate the risk associated with this type of threat (Mearns, Flin, \& O’Connor, 2001).

As with threats, the scenarios pilots reported included errors that were significantly more frequent in some operations than others. For instance, the error of intentional noncompliance refers to a pilot deliberately disobeying an aviation regulation or air traffic control instruction. This error occurred most commonly in scenarios involving charter operations and operations in the Other category. Within the current investigation, these two categories included several types of operations. Intentional noncompliance may be the result of a sense of personal invulnerability among pilots (Helmreich, 2000). However, it is unclear why this error would be more prevalent among these operational categories. Additional research, with a larger sample size, is required to piece apart the activities and levels of experience within the Charter and Other category to further explore this issue.

Proficiency errors were also significantly associated with the type of operation and were reported most frequently in flight instruction scenarios. As these errors refer to those of the responding pilot, this indicates a mistake on behalf of the instructor rather than the student. This finding may reflect a lack of technical expertise among many flight instructors, which is understandable as most instructors are apprentices or journeymen themselves. Unfortunately, proficiency errors may lead to risky situations when combined with the threat of student pilot error discussed previously. This finding suggests the need for investigation of flight instructor proficiency and for the identification of instructional methods that may be used to improve technical and nontechnical flight instructor skills. 
In scenarios where a specific nontechnical skill was identified, communication skills were reported more frequently in charter operations and, correspondingly, multi-crew situations. This is an intuitive finding, as although single pilots use communication skills with company personnel, air traffic control, and passengers, in a challenging scenario communication skills would have a more significant impact on multi-crews. Interestingly, as multi-crews were more likely to use communication skills in challenging situations, data indicated a slight tendency for single pilots to use situation awareness skills more often to maintain flight safety (a finding that approached significance, $p=.051$ ). These data therefore suggest a benefit for nontechnical skill training that is customized to the type of operation a pilot is involved in, with an emphasis on communication skills for multi-crews and situation awareness skills for single-pilot operations.

Overall, this investigation revealed some of the different threats, errors, and nontechnical skills within scenarios perceived as important by pilots within GA. Given that different operation and crew types were associated with specific threats, errors, and nontechnical skills, it is logical to suggest that the rate of development of specific types of nontechnical skills may vary depending upon the operations within which relevant experience was gained. This is contrary to the widely-held aviation industry assumption that expertise is accurately measured by a pilot's hours. The current study asked pilots to report on only one event from the hours-building phase of their career, and future studies will need to gauge pilot experience in a more objective fashion to more precisely determine how expertise is shaped by flight operations. Nonetheless, the current data suggest that flight hours alone may be an insufficient method of mapping nontechnical expertise development, as it potentially overlooks important skill differences between pilots associated with their operational experience.

\section{Acknowledgements}

The authors wish to acknowledge and sincerely thank the staff of Seneca College who assisted with several aspects of this investigation, including the production of the online survey, recruitment, and development of the electronic database. This project was funded by the College and Community Innovation Program from the Natural Sciences and Engineering Research Council of Canada. In addition, the authors wish to thank Glenn Priestley of the Canadian Council for Aviation and Aerospace, who commented on an earlier version of this manuscript. 


\section{References}

Chi, M. T. (2006). Two approaches to the study of experts' characteristics. In K. Ericsson, N. Charness, R. Hoffman, \& P. Feltovich (Eds.), The Cambridge handbook of expertise and expert performance (pp. 21-30). New York, NY: Cambridge University Press.

Doane, S. M., Sohn, Y. W., \& Jodlowski, M. T. (2004). Pilot ability to anticipate the consequences of flight actions as a function of expertise. Human Factors, 46(1), 92103.

Durso, F. T., \& Dattel, A. R. (2006). Expertise and transportation. In K. Ericsson, N. Charness, R. Hoffman, \& P. Feltovich (Eds.), The Cambridge handbook of expertise and expert performance (pp. 335-371). New York, NY: Cambridge University Press.

Ericsson, K. A. (2004). Deliberate practice and the acquisition and maintenance of expert performance in medicine and related domains. Academic Medicine, 79(10), S70-S81.

Helmreich, R. L. (2000). Culture and error in space: Implications from analog environments. Aviation, Space, and Environmental Medicine, 71(9), A133-A139.

Helmreich, R. L., Merritt, A. C., \& Wilhelm, J. A. (1999). The evolution of crew resource management training in commercial aviation. International Journal of Aviation Psychology, 9(1), 19-32.

Hoffman, R. R. (1996). How can expertise be defined? Implications of research from cognitive psychology. In R. Williams, W. Faulkner, \& J. Fleck (Eds.), Exploring expertise (pp. 81-100). Edinburgh, Scotland: University of Edinburgh Press.

Kearns, S. (2009). Canadian aviation. Dubuque, IA: Kendall Hunt.

Kearns, S., \& Sutton, J. E. (2011). Hangar talk survey: Identifying the threats and errors encountered naturalistically by pilots in general aviation. Manuscript submitted for publication.

Mearns, K., Flin, R., \& O’Connor, P. (2001). Sharing “worlds of risk”: Improving communication with crew resource management. Journal of Risk Research, 4, 377392.

Morrow, D. G., Soederberg Miller, L. M., Ridolfo, H. E., Magnor, C., Fischer, U. M., Kokayeff, N. K., \& Stine-Morrow, E. A. L. (2009). Expertise and age differences in pilot decision making. Aging, Neuropsychology, and Cognition, 16, 33-55. 
Taylor, J. L., Kennedy, Q., Noda, A., \& Yesavage, J. A. (2007). Pilot age and expertise predict flight simulator performance: A 3-year longitudinal study. Neurology, 68, 648-654.

Thomas, M. J. (2004). Predictors of threat and error management: Identification of core nontechnical skills and implications for training systems design. International Journal of Aviation Psychology, 14(2), 207-231.

Transport Canada. (2010). Licences in force - Professional and Recreational - 19882008. Retrieved from http://www.tc.gc.ca/eng/civilaviation/standards/generalpersonnel-stats-force-2303.htm

Transportation Safety Board. (2011). Aviation statistics. Retrieved from http://www.tsb.gc.ca/eng/stats/ aviation/2010-12/a12-2010.asp 